\title{
Storage capacity of a superposition of synfire chains using conductance-based integrate-and-fire neurons Chris Trengove* ${ }^{* 1,2}$
}

\author{
Address: ${ }^{1}$ The Bionic Ear Institute, 384-388 Albert St, East Melbourne, VIC 3002, Australia and ${ }^{2}$ Dept Otolaryngology, The University of \\ Melbourne, Melbourne, VIC 3010, Australia \\ Email: Chris Trengove* - ctrengove@bionicear.org \\ * Corresponding author
}

from Sixteenth Annual Computational Neuroscience Meeting: CNS*2007

Toronto, Canada. 7-12 July 2007

Published: 6 July 2007

BMC Neuroscience 2007, 8(Suppl 2):P67 doi: I0.I |86/I47|-2202-8-S2-P67

(C) 2007 Trengove; licensee BioMed Central Ltd.

\section{Background}

It has been proposed that the cortex could be a random superposition of synfire chains, in which waves propagating on the synfire chains account for the majority of the 5 $\mathrm{Hz}$ background activity observed in cortex [1]. This proposal is an alternative to other recent models that treat background activity as the stochastic firing of neurons in response to recurrent and external input in a sparse random network [2]. Here we study the synfire superposition model using a leaky integrate-and-fire spiking neuron with conductance-based synapses, along with the incorporation of inhibitory neurons into the chains, to establish whether the model is feasible and consistent with observed neurophysiology.

\section{Methods}

Storage capacity is analysed in terms of two constraints: spurious spiking rate stability and synfire wave propagation stability. An expression for the (spurious) spiking rate in response to excitatory and inhibitory background input has been obtained using a diffusion approximation [3]. A low spiking rate is achievable with high rates of background input in the regime where the mean of the fluctuating membrane potential is positioned sufficiently below the firing threshold. In this regime, a linear relationship between background input and spurious spiking rate is found. We use this to obtain a limit on the amount of connectivity available to store synfire links such that the network state of low spurious spiking rate remains stable and below the spiking rate due to synfire waves. For a given level of background activity $(5 \mathrm{~Hz})$ this equates to a limit on background input. Next, the minimum pool size for stable wave propagation is obtained for a given level of background input, via single-neuron simulations that determine the probability of firing in response to synfire wave input. This is done for plausible settings of three independent background input parameters (excitatory synaptic conductance, ratio of excitatory to inhibitory input connectivity per neuron, and number of standard deviations of mean potential below threshold). Simulations of wave propagation on synfire chains of varying pool size in the presence of varying levels of background input are used to verify the validity of the minimum pool size calculation. The optimal storage capacity is then found by minimising pool size and maximising connectivity subject to the two constraints.

\section{Results}

The minimum pool size for wave transmission as a function of background input as obtained by single-neuron simulations was in close agreement with the corresponding synfire chain simulations. High storage capacities in which the number of synfire pools exceeds the number of neurons in the network were found for plausible parameter choices. Cortically realistic levels of reinforced connectivity $\left(2 \times 10^{3}-2 \times 10^{4}\right.$ excitatory inputs per neuron) were also found. Storage was found to be optimised by a mean membrane potential positioned about 3.5-3.8 standard deviations below threshold. 


\section{Discussion}

The optimal position of the mean membrane potential is due to a trade-off between stability of wave propagation and stability of spurious firing, and is located only a few millivolts below threshold, in accordance with in vivo observations [4]. This implies an advantage for conductance-based over current-based synapses in the synfire superposition model: in the latter a much larger standard deviation is found for the same background input level [2] implying a much less favourable trade-off for synfire chain storage.

\section{References}

I. Bienenstock E: A model of neocortex. Network 1995, 6:179-224.

2. Meffin H, Burkitt AN, Grayden DB: An analytical model for the 'large, fluctuating synaptic conductance state' typical of neocortical neurons in vivo. J Comput Neurosci 2004, 16:159-175.

3. Burkitt AN, Meffin H, Grayden DB: Study of neuronal gain in a conductance-based leaky integrate-and-fire neuron model with balanced excitatory and inhibitory synaptic input. Biol Cybern 2003, 89: I19-125.

4. Destexhe A, Paré D: Impact of network activity on the integrative properties of neocortical pyramidal neurons in vivo. J Neurophysiol 1999, 81:1531-I547.

Publish with Bio Med Central and every scientist can read your work free of charge

"BioMed Central will be the most significant development for disseminating the results of biomedical research in our lifetime. "

Sir Paul Nurse, Cancer Research UK

Your research papers will be:

- available free of charge to the entire biomedical community

- peer reviewed and published immediately upon acceptance

- cited in PubMed and archived on PubMed Central

- yours - you keep the copyright

Submit your manuscript here:

http://www.biomedcentral.com/info/publishing_adv.asp 